msh-mss Mathématiques et sciences humaines

178 | Été 2007

Art, mathématiques, langage et émotion

\title{
Music and combinations
}

Combinaisons et musique

\section{Tom Johnson}

\section{OpenEdition}

Journals

Édition électronique

URL : http://journals.openedition.org/msh/4252

DOI : $10.4000 /$ msh.4252

ISSN : 1950-6821

\section{Éditeur}

Centre d'analyse et de mathématique sociales de l'EHESS

\section{Édition imprimée}

Date de publication : 1 juillet 2007

Pagination : 87-93

ISSN : 0987-6936

\section{Référence électronique}

Tom Johnson, « Music and combinations », Mathématiques et sciences humaines [En ligne], 178 | Été

2007, mis en ligne le 21 septembre 2007, consulté le 23 juillet 2020. URL : http://

journals.openedition.org/msh/4252 ; DOI : https://doi.org/10.4000/msh.4252 


\title{
MUSIC AND COMBINATIONS ${ }^{1}$
}

\author{
Tom JOHNSON ${ }^{2}$
}

\begin{abstract}
RÉSUMÉ - Combinaisons et musique
Nous tentons de décrire le processus compositionnel qui a dirigé notre écriture de la pièce «Combinations for String Quartet».

MOTS-CLÉS - Combinaisons, Composition mathématico-musicale, Permutations

SUMMARY - We give a tentative description of the composition process that directed our writing of the piece "Combinations for String Quartet.
\end{abstract}

KEY-WORDS - Combinations, Mathematico-musical composition, Permutations

Combinations for String Quartet (2003) contains five movements, and each of these contains all the combinations of something. As usual, I wanted the music to know what it was doing, to be correct and complete in a rigorous sense, and this is one way of achieving this. The theory of combinations is a totally explored mathematical discipline, as we have known for more than a century how to calculate all kinds of combinations and probabilities, and how to prove all of this. So what I say about my composition can not have fundamental significance for mathematics. I can, however, demonstrate that new questions arrive when one wants to go inside some set of combinations, to see how they come together, to observe the many symmetries within them, to find the best sequence for them, to consider how they might sound, to turn them into music.

\section{COMBINATIONS OF ABCD PERMUTATIONS}

The first movement had to do with the permutations of four notes (A,B,C,D). I wanted to use all 24 permutations, but I also wanted to find how the permutations could be combined so that all four notes would be present in four instruments at every moment. The most obvious solution was to let the four musicians all play the same thing starting at different points. Of course, one may change the sequence of the lines and still have the same four permutations:

\footnotetext{
${ }^{1}$ Lecture presented December 13, 2003 in a colloquium on Arts and Sciences sponsored by the association laMétive in La Creuse (France).

${ }^{2} 75$ rue de la Roquette 75011 Paris, tom@ johnson.org
} 


\section{$\mathrm{ABCD}$ \\ BCDA \\ CDAB \\ $\mathrm{DABC}$}

This was not musically very interesting, since everyone was essentially playing the same rising scale, so I looked for other possibilities. Of course, one could simply place the columns in five other positions,

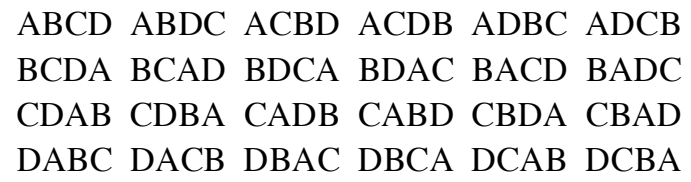

but in the five new solutions, the players now have different loops, and the canon structure is lost. How else could I solve the problem I had posed?

I found a more interesting solution by transposing letters, rather than simply moving them from left to right. By transposing pairs, then reversing the order, then transposing pairs again, and then reversing the order again, I ended up where I began.

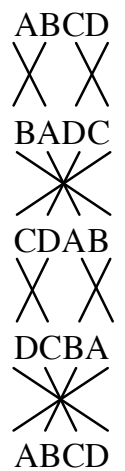

Now everyone is cycling either $\mathrm{ABCD}$, or $\mathrm{ADCB}$, which is the same thing backwards, and there is more coherence. The permutations sounded good played simultaneously, and I also liked them played in sequence as a melody. I could do the same thing beginning with $\mathrm{ABDC}, \mathrm{ACBD}, \mathrm{ACDB}, \mathrm{ADBC}$, and $\mathrm{ADCB}$, and obtain the rest of the 24 permutations, and that was really all I needed to know in order to write the piece.

A couple of months after writing the music, however, I wanted to understand better what I had done, and to discuss the problem with others, so I began to study the possibilities more thoroughly. Perhaps there were other solutions. I began with this question: If the first line is $\mathrm{ABCD}$ and the first column is also $\mathrm{ABCD}$, how many ways are there to fill the square, still having all four letters present in each line and in each column?

$$
\begin{aligned}
& \text { ABCD } \\
& \text { B } \\
& \text { C } \\
& \text { D }
\end{aligned}
$$

If one places $\mathrm{A}$ in the second position of the second line, one must continue filling the square in this way: 
$\mathrm{ABCD}$

BADC

$\mathrm{CD}$

DC

leading to two complete solutions:

- Solution One:

ABCD

BADC

CDAB

DCBA

- Solution Two:
$\mathrm{ABCD}$
BADC
CDBA
DCAB

If one places $\mathrm{C}$ in the second position of the second line, one must continue filling the square in the following way, which gives the solution mentioned at the beginning of the discussion, with everyone playing the same rising line starting at different points

- Solution Three:
$\mathrm{ABCD}$
BCDA
CDAB
$\mathrm{DABC}$

And if one places $\mathrm{D}$ in the second position of the second line, one must continue filling the square in this way:

- Solution Four:
$\mathrm{ABCD}$
BDAC
CADB
DCBA

I looked back at the music I wrote, placed the lines and columns in ABCD order and discovered that all six of the solutions I used are just reorderings of Solution One. Curiously, looking at the six additional squares decorating the cover, which had been calculated in a very different way, I found that these squares, unscrambled, were also rearrangements of Solution One. Should I perhaps have used Solutions Two, Three, Four, or all of these? That might have been more sophisticated mathematically, but I continue to be pleased with what I have in the score. If one looks at the first measure of each of the six tutti sections, for example, one finds a neat grouping of the 24 permutations. Two different melodic contours are always in counterpoint with one another. All 24 permutations occur in each of the four instruments. The list of combinations seems quite complete, even though I now know that I was working with only one fourth of the possibilities. 


$\begin{array}{lll}\text { Vn. I } & \text { ABDC CABD CBAD BCAD CADB CDAB } \\ \text { Vn. II } & \text { DCAB BDCA ADCB ADBC DBCA ABCD } \\ \text { Viola } & \text { BACD ACDB BCDA CBDA ACBD DCBA } \\ \text { Cello } & \text { CDBA DBAC DABC DACB BDAC BADC }\end{array}$

\section{COMBINATIONS OF EIGHT MOTIFS}

The other movements involved different kinds of combinations, so breaking them into groups and sequences was also different. In the fourth movement each instrument has two motifs, one of which is louder than the other. I remember that finding the actual motifs was not so problematic. In a rather short time I had my basic collection of eight motifs. Each had a special character, and they could sound fine in all the possible combinations. The problem was to find the sequence.

Probably the most obvious way to compile a list of these possibilities. would be to list the 8 combinations containing a single motif, followed by the 24 containing two motifs, the 32 containing three motifs, and the 16 containing four motifs, incrementing as one normally would in base-three counting. If for each instrument we call the loud motif " 2 ," the soft motif " 1 ," and silence " 0 ," the 80 combinations could be defined in this way:

$\begin{array}{lll}\text { Violin I } & 12000000 & 121212001200121200000000 \\ \text { Violin II } & 00120000 & 112200120012000012120000 \\ \text { Viola } & 00001200 & 000011112222000000001212 \\ \text { Cello } & 00000012 & 000000000000112211221122 \\ & & \\ & 12121212121212001200121212001200 & 1212121212121212 \\ & 11221122112200120012112200120012 & 1122112211221122 \\ & 11112222000011112222000011112222 & 111122221112222 \\ & 00000000111111111111222222222222 & 1111111122222222\end{array}$

Without having thought at all about sound and rhythm, we already have a musical logic here, as well as a mathematical logic. There is a general progression from the " 1 " motifs to the louder " 2 " motifs, and from solos to quartets. But there are many things that could be improved. The four sections are all of unequal length, giving a curious asymmetry. A single instrument sometimes repeats the same motif, or an alternation of two motifs, for quite a long time, which could be fatiguing for the performer, as well as for the listener. The logic is relatively easy to hear (or to see) in the first and last sections, but not immediately clear in the long internal sections. How could I improve the sequence of my 80 combinations.

I could not remember all the things I had tried and rejected and how I had arrived at a solution, so I did something I hardly ever do. I looked through my working sketches and attempted to determine how I found my way toward my final solution.

Judging from the early drafts, I observed rather quickly that I could compose the piece in eight equal groups of 10 combinations, since the lengths of the four groups, the 8 solos, the 24 duets, the 32 trios and the 16 quartets, were all divisible by eight. I liked the idea of finding a 10-combination structure, repeating it eight times, and achieving a nice symmetrical form, like a song with eight verses. Each 10-combination group would have 4 trios, 3 duets, 2 quartets, and one solo, and they would all have a similar 
structure. But there are many ways to order these 10-combination sections, and I tried quite a few.

One page of sketches organizes each sequence of ten combinations like this, though now I can't imagine why:

\section{trio trio duo trio duo quartet trio duet quartet solo}

I probably tried other sequences before determining that it was best to simply begin with the tutti combinations and progress to the solos.

\section{quartet quartet trio trio trio trio duet duet duet solo}

But the piece was still not finished. There were many additional things to consider in order to determine which of the 32 trio combinations would now fit best into the 32 slots available for trios, and several pages of numbers demonstrate that I tried quite a few techniques for this before arriving at this final choice:

$\begin{array}{lllll}\text { Violin I } & 2121212200 & 2121212200 & 2121211100 & 2121211100 \\ \text { Violin II } & 2121212020 & 2112121020 & 2121212010 & 1212121010 \\ \text { Viola } & 2121120220 & 2121120110 & 1200000221 & 2100000112 \\ \text { Cello } & 2100000001 & 1200000002 & 2121120000 & 2121120000 \\ & & & & \\ & 1221212000 & 2121211000 & 2100001002 & 2100002001 \\ & 2100000201 & 2100000102 & 1221210100 & 1221210200 \\ & 2121210020 & 1212120010 & 2121120010 & 1221120020 \\ & 2121122220 & 1221121110 & 1221212220 & 2112121110\end{array}$

This sequence pleases me much more than the $8+24+32+16$ arrangement we began with. First of all, the two quartet combinations that begin each of the eight sections are the inverse of one another. Each instrument plays each of its motifs within each pair of quartets. No repetition of motifs. A sharp contrast between two opening tuttis each time. The four three-motif combinations in each section employ only three instruments, leaving the fourth instrument to play the solo at the end of the section. The eight solos progress upwards from cello to Violin I.

Is this all just music, or is it not also rather nice to look at simply as numbers?

And is the difference between the $8+24+32+16$ arrangement I began with and the more elegant $8 \times 10$ arrangement I ended with purely a musical matter, or is it also relevant to the theory of combinations? Is combination theory just a matter of counting correctly the number of possibilities? Is it completely irrelevant how you do this?

\section{COMBINATIONS OF E-FLAT}

Let's look at the second movement of the Combinations for String Quartet, which involves quite another problem. Here I wanted a one-pitch piece with four E-flats in four instruments in four octaves, so there could be only 15 combinations, four solos, six duets, four trios and one quartet: 


$\begin{array}{lllll}\text { Violin I } & 1000 & 111000 & 1110 & 1 \\ \text { Violin II } & 0100 & 100110 & 1101 & 1 \\ \text { Viola } & 0010 & 010101 & 1011 & 1 \\ \text { Cello } & 0001 & 001011 & 0111 & 1\end{array}$

This was too short to be a complete movement, so I found a logical way of transforming these 15 combinations into several variations. Again I dug out the working sketches to try to determine how the movement had evolved. In one sketch I began with this obvious sequence, which we can call 123456789101112131415 , composed the next section by taking alternative combinations: 135791113152468101214 , then alternative combinations from that list: 159132610143711154812 , then alternative combinations from that list: 192103114125136147158 , then once again, bringing us back to 123456789101112131415 . This seems rather clever, and there are several pages of sketches that follow this scheme, but it is very hard to hear this logic. The solo-duet-trio-quartet organization disappears after the original sequence, and one also hears little order if one listens to one particular instrument.

I found a more satisfying solution with this same procedure by changing the original sequence so that Violin I plays a bar and rests a bar in alternation, while the second violin plays two bars rests two bars in alternation, the viola plays four bars rests four bars in alternation, and the cello plays the first eight bars and rests the last eight bars. For a mathematician this is binary counting from 15 down to 1 .

$\begin{array}{ll}\text { Violin I } & 101010101010101 \\ \text { Violin II } & 110011001100110 \\ \text { Viola } & 111100001111000 \\ \text { Cello } & 111111110000000\end{array}$

Following the same shuffling procedure, beginning with this as a starting point, the result was quite pleasing for me. Playing through the new structure at the piano, each of the four transformations had a pleasing sound and had the kind of logic I was looking for, no doubt partly because each section now began with a quartet and ended with a solo in a similar way:

$\begin{array}{lllll}101010101010101 & 111111110000000 & 111100001111000 & 110011001100110 \\ 110011001100110 & 101010101010101 & 111111110000000 & 111100001111000 \\ 111100001111000 & 110011001100110 & 101010101010101 & 111111110000000 \\ 111111110000000 & 111100001111000 & 110011001100110 & 101010101010101\end{array}$

I recall now how I realized a few days later, with some embarrassment, that what I was doing here was not a sophisticated transformation process at all, but simply a canon. The $1010 \ldots$ line appears in the first violin in the first section, in the second violin in the second section, in the viola in the third section and in the cello in the fourth section, and in fact, all four instruments are simply playing the same thing with different starting points.

There is something reassuring when one follows one logic and finds that one is unconsciously following a second logic at the same time, and this helped to convince me that I should leave my little collection of E-flats in this form.

There remained one problem. Was the composition complete in this four-section form, or would it be better to make one more transformation, producing a fifth section that would be the same as the first? There is no clear answer here. It is nice to make a 
complete rotation and restate the starting point, but it is also logical to do everything once and only once. I decided to complete the circle and make it a five-section piece.

The other two movements are concerned with other kinds of combinations, and we could look at those as well, but I have already presented enough information for you to see what it is like for me, working inside a collection of combinations, rather than simply counting them, so I will just pose two more questions and stop.

- Question: Were my final choices only my opinion, or would others agree that I was placing my combinations in the most pleasing arrangement?

- My Answer: I am convinced that there is something absolute here, perhaps even provable, and that others would also find my solutions more satisfying than other sequences of the same combinations.

- Question: Was I only doing music as I moved toward this structure?

- My Answer: I don't know.

Petite bibliographie complémentaire proposée par Claude Le Conte de Poly-Barbut ${ }^{3}$.

COUMET E., Mersenne, Frenicle et l'élaboration de l'analyse combinatoire dans la première moitié du XVII ${ }^{e}$ siècle, thèse, Paris, décembre 1968.

[E. Coumet a consacré une partie de sa thèse aux travaux de Mersenne (1588-1648, France), prêtre de l'ordre des Minimes dont l'ouvrage « Harmonie universelle - livre des chants » rend compte de ses travaux combinatoires, entre autres: combinaisons, combinaisons simples (nos permutations), arrangements et de certaines utilisations en musique. Les travaux de Mersenne sont cités dans le dictionnaire de Furetière : "La combination de notes de musique presque à 64 qui est contenue en 90 chiffres » et repris par Trévoux et dans l'Encyclopédie].

GUILBAUD G. TH., ROSENSTIEHL P., «Analyse algébrique d'un scrutin », Ordres totaux finis, Paris, Gauthier Villars, La Haye, Mouton, 1971.

[Cet article, repris d'un premier publié dans le n 4, 1963 de Mathématiques et Sciences humaines, donne un exemple bien connu d'une structure de treillis sur l'ensemble des ordres totaux : le permutoèdre qui à son tour peut structurer des données se présentant sous forme d'ordres totaux ou permutations finies].

BERGE C., Principes de combinatoire, Paris, Dunod, 1968.

COMTET L., Analyse combinatoire, tome I et II, Paris, Presses Universitaires de France, 1970, [réédition 1985].

[Ces deux ouvrages très clairs font partie de toute bibliothèque de combinatoire].

\footnotetext{
${ }^{3}$ Centre d'Analyse et de Mathématique Sociales (CAMS), École des Hautes Études en Sciences Sociales (EHESS), 54 bd Raspail 75270 Paris Cedex 06, barbut@ehess.fr
} 